At present the big cause for concern is the effect on anaesthetists of the drugs they administer. Those working in small poorly ventilated theatres accumulate inhalational anaesthetic drugs in their tissues and release them slowly. ${ }^{4}$ Contamination of the atmosphere is not necessarily confined to the theatre but may also be found in areas where patients recover. ${ }^{5}$ Repeated exposure to halothane leads to induction of liver microsomal enzyme systems; and this suggests that increased breakdown to trifluoroacetic acid, trifluoroacetyl ethanolamine, and free chloride and bromide might occur in anaesthetists who are repeatedly exposed. The accumulation of bromide ions, which are known to be slowly eliminated via the kidneys and skin, might even conceivably cause impairment of thought processes.

In order to monitor his patients closely the anaesthetist relies on auditory, visual, tactile, and even olfactory stimuli. It follows that the sensory pathways, the recognition, perception, and integration of these signals, decision making, and the motor pathways must not be impaired. Lack of adequate rest periods coupled with long hours in the theatre environment may lead to an impairment of these functions, ${ }^{4}$ an effect that may be compounded by chronic exposure to inhalational agents. ${ }^{6}$ Psychometric tests carried out on volunteers after exposure to nitrous oxide with or without halothane in concentrations comparable with those measured in theatre atmospheres have shown a decrease in ability as measured by performance tests.

Long-term exposure of animals to clinical concentrations of inhalational agents is known to produce teratrogenic effects and interfere with the immune response. Nitrous oxide can influence the white count in man and can cause fetal reabsorption and intrauterine death in rats. Whether such effects can be produced by prolonged contact with contaminated theatre atmospheres is not known. However, in 1967, the report that 18 of 31 pregnancies among 303 female Russian anaesthetists terminated in spontaneous abortion provoked renewed interest in the question. In 1970 Askrog and Harvald ${ }^{7}$ reported a high rate of spontaneous abortion among anaesthetists in Denmark, and in 1972 Knill-Jones et al. ${ }^{8}$ studied 563 married women anaesthetists and found the frequency of spontaneous abortion to be higher when anaesthetists were working than when they did not work. The miscarriage rate and the incidence of congenital abnormalities and involuntary infertility were lower in a control group. A study ${ }^{2}$ just completed by the American Society of Anesthetists and the National Institute for Occupational Safety and Health has shown clearly that there is an increased risk of spontaneous abortion among women anaesthetists and that congenital birth defects have an increased incidence among children of anaesthetists of both sexes. Whether such problems are due to pollution of the theatre atmosphere with inhalational anaesthetic agents or are due to the general working conditions remain to be determined. Until this has been established pollution should be reduced by using apparatus designed either to contain the gases (closed circuit) or to vent them out of the theatre environment. As charcoal absorbents do not clear nitrous oxide their use is possibly limited to situations when agents such as halothane are used alone.

It is welcome news that the Association of Anaesthetists of Great Britain and Ireland has set up a working party with the D.H.S.S. to consider the matter.

\footnotetext{
1 Bruce, D. L., et al., Anesthesiology, 1974, 41, 71.

2 Report of an Ad Hoc Committee on the Effect of Trace Anesthetics on the Health of Operating Room Personnel, American Society of Anesthesiologists, Anesthesiology, 1974, 41, 321. 3 Spence, A. A., et al., Proceedings of the Royal Society of Medicine, 1974,
67, 989.
}

4 Gostomzyk, J. G., et al., Anaesthestist, 1973, 22, 469.

Yanagida, H., et al., Anesthesia and Analgesia, 1974, 53, 347.

Bruce, D. L., et al., Anesthesiology, 1974, 40, 453.

Askrog, V., and Harvald, B., Nordisk Medicine, 1970, 83, 498

Knill-Jones, R. P., et al., Lancet, 1972, 1, 1326. Wilkinson, R. T., Proceedings of the Royal Society of Medicine, 1974, 67,
994.

\section{A Nit or Not a Nit?}

The number of school children with head lice is apparently still rising. ${ }^{1}$ In 1969 Wilson reported ${ }^{2}$ that in Glasgow infestation in school girls was as common as in the 1930'snearly $10 \%$ of school entrants had nits-and that in boys the incidence had increased, with about $4 \%$ of school entrants having nits compared with less than $1 \%$ in the 1930's. He thought that this increase was due to the fashion of longer hair in boys. Two years later higher rates of infestation were found in Teeside, where Coates ${ }^{3}$ estimated that about one in every eight of the children was verminous on return to school at the beginning of one autumn term. Maunder ${ }^{4}$ showed that lice obtained from an east London school were resistant to both DDT and gammexane and he subsequently reported ${ }^{5}$ that malathion was effective in controlling the infestation. This was confirmed in a study ${ }^{6}$ in Northern Ireland, but nearly one-fifth of the children were reinfested two months after treatment.

Though there has been an increase in head infestation in children in Britain, probably owing to a combination of the development of drug resistance in lice and to the changing fashions in the style and care of hair, head infestation is sometimes misdiagnosed and some of the reported increase may be spurious. Kutz ${ }^{7}$ reported an incident where an extensive infestation with "nits" proved to be a misdiagnosis, for the so-called nits were shown to be minute pieces of scalp which had become glued around the hair, probably by hair spray. In another "outbreak" small opaque globules attached to the hair were mistaken for nits. ${ }^{8}$ These episodes illustrate the importance of confirming the diagnosis of infestation by expert examination with a lens, particularly in the absence of adult lice.

Malathion lotion $(0.5 \%$ in spirit) has been shown to be effective in killing lice and nits resistant to DDT and gammexane and also to have a residual effect in the scalp. It seems now to be the treatment of choice in areas where resistance has appeared. In these areas malathion treatment should completely replace treatment with DDT and gammexane. The treatment with malathion is simple: the lotion should be applied freely to the scalp and then allowed to dry (heat should not be applied because the lotion is spirit based and therefore inflammable). The head should not be washed until about 24 hours after the application of the malathion, and then shampooing and combing may be carried out to remove the dead nits.

Head louse infestation is usually a family condition, so that treatment should not be confined to the school child if reinfestation is to be avoided. The nurse should visit the house of the affected child and explain that infestation is spread by close contact, irrespective of the state of cleanliness, and that lice do not imply a "dirty head." She should then offer malathion treatment to all members of the household, whether or not she can verify current infestation, because only by family treatment can eradication be achieved.

Resistance of lice to malathion may soon appear in Britain; Silverton ${ }^{9}$ quoted a case where malathion treatment appeared 
to be ineffective. Maunder ${ }^{4}$ showed that the lice resistant to the DDT and gammexane were susceptible to carbaryl as well as to malathion. Trials of carbaryl preparations are at present in progress: there is hope that we shall remain one step ahead of the louse in future.

\footnotetext{
${ }^{1}$ Department of Education and Science, The Health of the School Child 1971-72. London, H.M.S.O., 1974

2 Wilson, T. S., Medical Officer, 1969, 122, 125

3 Coates, K. G., Community Medicine, 1971, 126, 148.

${ }^{4}$ Maunder, J. W., Medical Officer, 1971, 125, 27.

5 Maunder, J. W. Medical Officer, 1971, 126, 145.

6 Maguire, J., and McNally, A. J., Community Medicine, 1972, 128, 374.

7 Kutz, F. W., Entomological News, 1969, 80, 27.

8 Gemrich, E. G., et al., American fournal of Public Health, 1974, 64, 805.

9 Silverton, N., British Medical fournal, 1972, 3, 646.
}

\section{Osteosarcoma-New Hope?}

Osteosarcoma most often affects the lower end of the femur, and within two years four out of five victims of this particularly unpleasant tumour are dead. Most are but children, whose lungs remain free of metastases for no more than ten months after starting treatment, and who die six months later. A dismal picture indeed, relieved only by advances in palliation and the sparing of amputation in some by the use of radiotherapy alone in those whose fate is already sealed by the early development of lung metastases. Indeed Cade's advocacy $^{1}$ of this use of radiotherapy as a holding treatment before advising amputation only in those most likely to survive is almost the only real advance in treatment since amputation was first performed, and even this has not improved the chances of survival. ${ }^{2}$

As years have passed, the tumour's reputation for relative resistance to radiotherapy has changed little. More modern techniques have resulted in a better response, but amputation has remained the sheet anchor of definitive treatment. Chemotherapy began with a similar poor reputation, but the picture began to change two years ago with reports by $\mathrm{Jaffe}^{3}$ and Cortes et al. ${ }^{4}$ of regression of pulmonary metastases in patients with osteosarcoma. Within the last few weeks there have been further encouraging reports of the value of chemotherapeutic agents given prophylactically as adjuvant treatment after amputation. Jaffe et al., ${ }^{57}$ using a combination of high dose methotrexate (with citrovorum-factor) and vincristine, reported 11 patients out of 12 still free of metastases between 6 and 27 months after amputation. Similarly Cortes et al. ${ }^{67}$ using doxorubicin (adriamycin) reported 10 out of 13 patients apparently free of disease, 9 to 40 months after amputation. An indication that these figures may represent more than just delay in metastases is given by Sutow et al., ${ }^{8}$ who used a fourdrug combination including doxorubicin and had 10 out of 18 patients with no evidence of metastases 15 months or longer after amputation; at their latest analysis ${ }^{7}$ there had been no recurrence in any of them 9 to 23 months after finishing chemotherapy-no less than 27 to 40 months after amputation.

All this is most heartening, but it is early days. Nevertheless these American results are in line with early experience in Britain of similar chemotherapeutic regimens. No controlled clinical trials have been reported, but the apparent advantage conferred by chemotherapy now makes any attempt at such a true clinical trial unwarranted. Comparison, therefore, can be only with past experience.

Much more experience using different dosages and combinations of chemotherapeutic agents is now needed in order to find the best. However, with such a rare tumour as osteo- sarcoma it would be an advantage if many centres combined together to produce an early answer; and the Medical Research Council have set up a working party to co-ordinate a national trial of such prophylactic adjuvant treatment.

No doubt, in spite of some potentially serious side effects, these encouraging reports will result in widespread acceptance of adjuvant chemotherapy in osteosarcoma. Apart from serious complications a host of unpleasant side effects can occur. Total alopecia, for example, is an almost invariable (but fortunately temporary) result of treatment with doxorubicin. Other problems will present themselves to the clinician who at present favours Cade's method of delayed selective amputation after radiotherapy. No longer, it seems, can it be said that seven months after beginning treatment about $70 \%$ of those who will die of their disease will by then show evidence of lung metastases. The use of radiotherapy before amputation will now be open to debate, for the successes reported came from adjuvant chemotherapy given after primary rather than delayed amputation. Indeed Jaffe et al. stress the importance of amputation, claiming that any incomplete control of the primary tumour might encourage the development of resistent cells.

The Medical Research Council trial of adjuvant chemotherapy will receive widespread support from clinicians, radiotherapists, and orthopaedic surgeons alike. There can be few more heart-rending tasks in medicine than the management of a child with osteosarcoma, and the sooner the best adjuvant regimen is established from the results of a large trial the better.

\footnotetext{
1 Cade, S., Fournal of the Royal College of Surgeons of Edinburgh, 1955, 1,79. Sweetnam, R., Knowelden, J., and Seddon, H., British Medical fournal, $1971,2,363$.

3 Jaffe, N., Cancer, 1972, 30, 1627.

Cortes, E. P., et al., in Bone-Certain Aspects of Neoplasia, ed. G. H. G. Price and F. G. M. Moss. London, Butterworths, 1973.

5 Jaffe, N., et al., New England fournal of Medicine, 1974, 291, 994.

6 Cortes, E. P., et al., New England fournal of Medicine, 1974, 291, 998.

'Burchenal, J. H., The New England fournal of Medicine, 1974, 291, 1029.

${ }^{8}$ Sutow, W. W., Sullivan, M. P., and Fernbach, D. J., Proceedings of the American Association for Cancer Research, 1974, 15, 20.
}

\section{And About Time Too}

At last a Government Health Minister has admitted that the N.H.S. can no longer (if it ever could) claim to provide a comprehensive service. Last week Dr. David Owen, Minister of State for Health, told ${ }^{1}$ a conference of community health councils that "the Health Service is a rationed service. There will never be a government or a country that has enough resources to meet all the demands any nation will make on a national health service."

This belated ${ }^{2}$ recognition that medical care will need to be rationed is nevertheless welcome. Dr. Owen suggests that a national organization should be set up for the 207 community councils in England and Wales to give them a voice in the formation of health policies. The timetable he proposes, however-a steering committee to report in a few months time, then further delay before regulations are laid before Parliament-suggests that the urgency of the situation has still not been appreciated at the D.H.S.S.

Hospital building has virtually ceased. We described the confusion and despair at Leeds ${ }^{3}$ last week, but the pattern is the same at scores of other hospitals. Haemophiliac children are not given the treatment that could save them from permanent joint damage $;{ }^{4}$ patients with kidney disease die with no offer of dialysis $;^{5}$ waiting lists for "non urgent" 